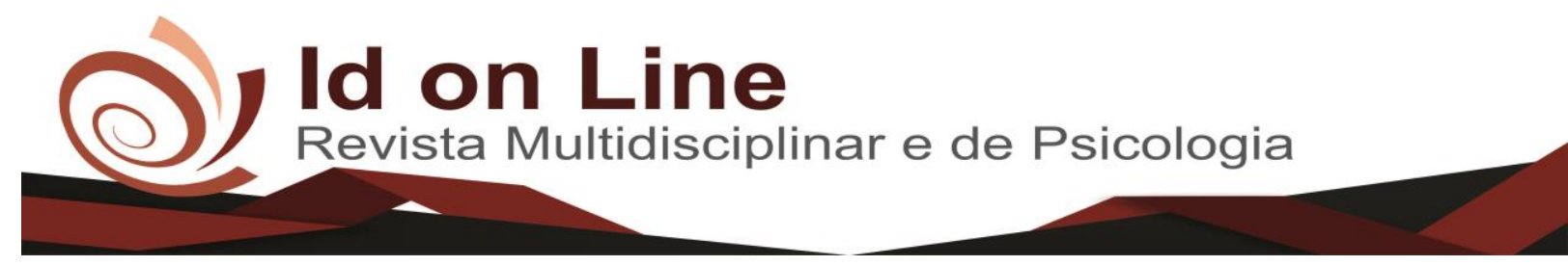

Estudo de Caso

\title{
Orçamento Participativo e Gestão Social: O Município de Juazeiro/BA e suas experiências participativas
}

\author{
Alexsandro de Jesus Mota ${ }^{1 *}$; Marcelo Henrique Pereira dos Santos ${ }^{2}$
}

\begin{abstract}
Resumo: Com a redemocratização da sociedade brasileira, a nova constituição promulgada em 1988 prevê uma democracia representativa e participativa. Esse novo cenário democrático brasileiro resultou na municipalização das políticas públicas em que o prefeito e os cidadãos decidem juntos o futuro de seu município. O objetivo deste trabalho é fazer uma análise das experiências participativas no município de Juazeiro/Bahia nos últimos dez anos. Observando junto aos programas da Prefeitura a participação do cidadão nos planejamentos orçamentários do município, considerando o modelo de Orçamento Participativo. A metodologia consistiu em uma análise documental descritiva sobre os programas de Políticas Públicas no município. A resultante desta análise permitiu identificar que embora o orçamento participativo não tenha sido institucionalizado no município, os cidadãos juazeirenses vem dando a sua contribuição na definição do orçamento municipal junto aos programas realizados pela Prefeitura Municipal de Juazeiro.
\end{abstract}

Palavras-chave: Orçamento Participativo, Planejamentos, Políticas Públicas.

\section{Participatory Budget and Social Management: The City of Juazeiro of Bahia and its Participatory Experiences}

\begin{abstract}
With the redemocratization of Brazilian society, the new constitution enacted in 1988 provides for a representative and participatory democracy. This new Brazilian democratic scenario resulted in the municipalization of public policies in which the mayor and citizens jointly decide the future of their municipality. The objective of this work is to make an analysis of participatory experiences in the municipality of Juazeiro / Bahia in the last ten years. Observing with the programs of the City Hall the participation of the citizen in the budgetary planning of the municipality, considering the model of Participative Budget. The methodology consisted in a descriptive documentary analysis on the Public Policy programs in the municipality. The result of this analysis allowed to identify that although the participatory budget has not been institutionalized in the municipality, the citizens of Juárez have been giving their contribution in the definition of the municipal budget next to the programs realized by the Municipality of Juazeiro.
\end{abstract}

Key words: Participatory Budgeting, Planning, Public Policies.

\footnotetext{
${ }^{1}$ Pós-graduando em Gestão Pública pela Universidade Federal do Vale do São Francisco (UNIVASF-SEAD), Bacharel em Teologia pela Faculdade Teológica Batista do Paraná e Graduando em Ciências Sociais (Licenciatura) pela Universidade Federal do Vale do São Francisco (UNIVASF). Contato: alex_jmota@hotmail.com;

${ }^{2}$ Doutor em Ciências Sociais (Política) pela Pontifícia Universidade Católica de São Paulo, Mestre em Ciências Sociais (Política) pela Pontifícia Universidade Católica de São Paulo e Graduado em Ciências Sociais pela Pontifícia Universidade Católica de São Paulo.

*Autor para correspondência: Alexsandro de Jesus Mota, Rua Caraibeira, No 01-B, Cajueiro, Juazeiro-BA, CEP 48904 069.alex_jmota@hotmail.com.(74)99129-9596.
} 


\section{Introdução}

Em meados da década de 70 o Brasil passou por um período de desequilíbrio financeiro originado pela segunda crise do petróleo que culminou com a queda depois de 21 anos do modelo econômico do regime militar ao mesmo tempo em que o governo enfrentava forte pressão política devido ao descontentamento da sociedade. No final da década de 80 o Estado nacional foi pressionado a passar por um processo de redemocratização esperando que sua harmonia com os municípios fosse capaz de vigorar em novas funções e obrigações. Frente às crises que afetavam a política e economia brasileira, ficou claro que eram necessárias mudanças inovadoras na administração pública tradicional que indicassem um novo modelo de relação entre Estado e sociedade, por meio de uma gestão participativa.

Diante desse cenário iniciou-se um processo de inovação que caracterizou a trajetória das Políticas Públicas definida como um conjunto de projetos, programas e atividades realizadas pelo governo, fundamentada, sobretudo na efetivação dos direitos sociais (SILVA et al., 2018).A Constituição Federal de 1988 apresentou uma nova forma de planejamento e gestão das Políticas Públicas que partiria dos municípios para os estados, estabelecendo novos mecanismos nas tomadas de decisões e inovando a interação entre governo e sociedade, através de estratégias de participação social. A proposta era a descentralização do Estado e a municipalização da gestão pública, transformando a cidade em um espaço político (ROCHA, 2009; BARBOSA, 2010).

Dentro das políticas públicas destacam-se as políticas de Gestão Social e Orçamento Participativo, alternativas inovadoras que fortalecem o novo modelo de relações entre Estado e sociedade frente aos desafios no processo de transformação nas esferas: econômica e social, aonde vêm ganhando cada vez mais força dentro dos municípios brasileiros. A implantação de uma Gestão Social e Orçamento Participativo tiveram papel fundamental no processo de descentralização político-administrativa e na municipalização das políticas públicas, transformando e fortalecendo as instituições democráticas no país. Trata-se assim de um novo modelo institucional, regulamentado pela Constituição Federal de 1988, na execução de uma gestão descentralizada, democrática participativa em que o cidadão passa a ter voz ativa nas tomadas de decisões da sua cidade. 
O município de Juazeiro está localizado na região do norte do estado da Bahia, na microrregião homogênea do Baixo Médio São Francisco. Possuindo uma extensão territorial de $6.390 \mathrm{~km}$, o município é constituído de bairros, localidades e 9 distritos, apresentando uma estimativa populacional de 215.183 habitantes. Inserida na Região Administrativa Integrada de Desenvolvimento do Pólo Petrolina e Juazeiro, destaca-se pela agricultura irrigada. A cidade de Juazeiro é apontada como o município mais industrializado do vale do São Francisco, considerando que seu distrito industrial compõe diversas indústrias e outros tipos de empresas. Ocupando o primeiro lugar do estado e o sexto do país na geração de emprego de carteira assinada em 2017, Juazeiro tornou-se índice com 100\% dos indicadores positivos de políticas de desenvolvimento no estado da Bahia(IBGE, 2018).

Neste contexto, busca-se estabelecer uma melhor compreensão da participação popular nas decisões e acompanhamento do planejamento orçamentário municipal em Juazeiro/BA, a fim de que se alcance o entendimento de sua funcionalidade a partir das seguintes indagações: Como funciona a participação popular? De fato, há uma participação popular no orçamento e nas decisões do governo? Como se dá o acompanhamento do planejamento orçamentário municipal? A prefeitura juazeirense, tem demonstrado iniciativas que corroborem nessa dinâmica?

\section{Metodologia}

O artigo pretende fazer uma breve análise das experiências participativas das políticas públicas no município de Juazeiro através da implementação, desenvolvimento, desempenho da prefeitura e comunidade e resultados dos programas de governo entre os anos de 2009 e 2018, dando uma maior atenção aos Programas Prefeitura nas Comunidades e Prefeitura Cidadã (Tabela 1), apresentando dentro dos programas os conhecimentos do Orçamento Participativo no município. Para isso, foi realizada uma pesquisa qualitativa e descritiva através da análise documental de fonte primária e secundária baseadas em informações disponibilizadas pela Prefeitura Municipal de Juazeiro-BA, publicações periódicas, arquivos disponibilizados na internet, bem como as legislações federais e municipais consultadas (Tabela 2). 
Tabela 1.Principais Programas implantados pela prefeitura em Juazeiro/BA

\begin{tabular}{|c|c|c|c|}
\hline Programa & Objetivo & Divisão Regional & $\begin{array}{c}\text { Participação } \\
\text { Social }\end{array}$ \\
\hline $\begin{array}{c}\text { Prefeitura nas } \\
\text { Comunidades } \\
(2009-2017)\end{array}$ & $\begin{array}{l}\text { Envolver a população de forma organizada } \\
\text { no planejamento e na definição das } \\
\text { prioridades para o município nas diversas } \\
\text { áreas, a serem desenvolvidas a curto, médio e } \\
\text { longo prazo, de maneira que se construa um } \\
\text { plano de governo descentralizado o mais } \\
\text { próximo possível do conjunto da } \\
\text { População. }\end{array}$ & $\begin{array}{l}\text { Dezoito regiões } \\
\text { administrativas }\end{array}$ & Plenárias \\
\hline $\begin{array}{l}\text { Prefeitura } \\
\text { Cidadã } \\
(2017-)\end{array}$ & $\begin{array}{l}\text { Criar espaços permanentes para o diálogo } \\
\text { entre o Governo Municipal e a população, } \\
\text { para obter o diagnóstico correto das } \\
\text { demandas de cada comunidade, através dos } \\
\text { agentes públicos das diversas secretarias da } \\
\text { Prefeitura. }\end{array}$ & $\begin{array}{c}\text { Três regiões } \\
\text { administrativas }\end{array}$ & $\begin{array}{c}\text { Reuniões dos } \\
\text { Conselhos } \\
\text { Comunitários }\end{array}$ \\
\hline
\end{tabular}

Fonte: Site da Prefeitura de Juazeiro/BA

Tabela 2. Legislação Consultada

\begin{tabular}{c|c|c|l}
\hline Diploma & Âmbito & $\mathbf{N}^{\circ} /$ Ano & \multicolumn{1}{c}{ Emendas } \\
\hline Lei & Federal & $101 / 2000$ & $\begin{array}{l}\text { Estabelece normas de finanças públicas voltadas } \\
\text { para a responsabilidade na gestão fiscal }\end{array}$ \\
\hline Lei & $\begin{array}{c}\text { Municip } \\
\text { al }\end{array}$ & $1.767 / 2003$ & $\begin{array}{l}\text { Institui o Plano Diretor de Desenvolvimento Urbano } \\
\text { de Juazeiro. }\end{array}$ \\
\hline Decreto & Federal & $7.185 / 2010$ & $\begin{array}{l}\text { Dispõe sobre o padrão mínimo de qualidade do } \\
\text { sistema integrado de administração financeira e } \\
\text { controle, no âmbito de cada ente da Federação. }\end{array}$ \\
\hline Lei & $\begin{array}{c}\text { Municip } \\
\text { al }\end{array}$ & $2.300 / 2013$ & $\begin{array}{l}\text { Dispõe sobre as diretrizes orçamentárias para o } \\
\text { exercício de 2013. }\end{array}$ \\
\hline Decreto & $\begin{array}{c}\text { Municip } \\
\text { al }\end{array}$ & $565 / 2016$ & $\begin{array}{l}\text { Regulamenta o acesso à informação pública pelo } \\
\text { cidadão. }\end{array}$ \\
\hline
\end{tabular}

Fonte: Elaboração dos autores, 2018

\section{Resultados e Discussão}

A cidade de Juazeiro/BA vem avançando gradativamente e positivamente nas políticas públicas municipais, alcançando metas consideráveis no setor de desenvolvimento social, econômico e político, que visam o bem estar e o crescimento da comunidade. Os programas da Prefeitura vêm promovendo desenvolvimento significativo nos últimos dez anos nas políticas 
públicas do município, priorizando a participação dos cidadãos nas definições das ações do governo para a cidade juazeirense. É importante observar que os programas desenvolvidos na cidade de Juazeiro têm como prioridade o exercício de uma gestão social incentivando a participação popular na definição, execução, avaliação e revisão das políticas públicas no município, visto que "o cidadão é peça fundamental na política, posto que sem ele não seja possível efetivá-la no lócus de convivência, o município” (TEIXEIRA, 2002).

Nesse novo modelo de gestão, o Estado deixa de ser o centro detentor do poder para se tornar um dos atores na transformação da sociedade. É papel fundamental do Estado, garantir a igualdade e inclusão social na formulação de políticas públicas através de uma gestão social aberta e participativa visando o interesse coletivo. No entanto, os programas de políticas públicas enfrentam grandes entraves quando colocado à prova, sua eficiência e dimensão do alcance social. Como enfatiza Santo e Pinheiro (2017, p.202) existe "uma discussão frente à efetivação das políticas públicas em relação ao processo de construção, no que diz respeito à importância da participação da sociedade nas tomadas de decisões na gestão destes programas". Não basta dizer que o espaço é democrático e participativo, é necessário que as decisões sejam de fato acertadas coletivamente e que todos tenham conhecimento de todo o processo através da transparência de informações. A efetivação de uma gestão democrática cada vez mais participativa entre Estado e sociedade é a chave mestra para o controle social e estável de políticas públicas (OLIVEIRA et al., 2010).

Nesse sentido, a participação do cidadão na gestão municipal está prevista no Art. $2^{\circ}$ da Lei $\mathrm{n}^{\circ} 10.257$ de junho de 2001,Estatuto da Cidade.

\footnotetext{
“A política urbana tem por objetivo ordenar o pleno desenvolvimento das funções sociais da cidade e da propriedade urbana, mediante uma gestão democrática por meio da participação da população e de associações representativas dos vários segmentos da comunidade na formulação, execução e acompanhamento de planos, programas e projetos de desenvolvimento urbano". (BRASIL, 2001).
}

Por sua vez, o Art, $2^{\circ}$ do Plano Diretor Urbano do município de Juazeiro, instituído pela Lei $n^{\circ} 1.767,22$ de dezembro de 2003também prevê uma maior participação do cidadão na condução das políticas.

“O Plano Diretor Urbano objetiva dotar a Cidade de políticas públicas para promover o desenvolvimento urbano planejado de forma integrada, recuperando o ambiente natural e reestruturando a ocupação urbana no sentido de melhorar a qualidade de vida de seus habitantes, (...). IV - Reestruturação e modernização da administração 
municipal da qualificação profissional dos quadros de pessoal da atualização da legislação urbanística e administrativa, e principalmente da ampla participação da comunidade na definição e condução dessas políticas, e na capacidade de negociar com as esferas estadual e federal, os investimentos que ultrapassam a competência municipal."(JUAZEIRO, 2003).

Entretanto, só existem mudanças e avanço nas políticas públicas de uma cidade quando ocorrem mudanças favoráveis também na esfera política. É necessário que o poder político se interesse e se envolva com as causas sociais em todos os âmbitos das políticas públicas do seu município e esteja aberto e acessível para escutar e considerar as opiniões dos seus cidadãos, visando um maior crescimento e fortalecimento municipal e gestão democrática.

Nesse sentido, os programas e projetos desenvolvidos pela Prefeitura de um município parte do ideário voltado ao desenvolvimento nas principais carências e demandas consideradas prioritárias dentro das várias áreas sociais observadas na cidade. As ações da Prefeitura através dos programas e projetos devem está pautadas na implantação de uma Gestão Social, transparente e participativa envolvendo diversos setores da sociedade, através de audiências em que são apresentados principalmente os problemas públicos, na qual o cidadão poderá opinar e ajudar a planejar e solucionar esses problemas, melhorando o desenvolvimento da cidade. Do ponto de vista de Dias e Matos (2012), delimitar um problema público é fundamental no processo de elaboração de uma política pública de um município,embora a definição oficial do problema seja temporária, visto que os problemas públicos podem ser redefinidos e ajustados por alguns dos atores envolvidos durante o processo.

Dias e Matos ainda destacam,

\footnotetext{
"Para que uma política de governo se converta em políticas públicas, é necessário que esta se baseie em programas concretos, critérios, linhas de ação e normas; planos; previsões orçamentárias, humanas e materiais; também podem ser incluídas as disposições constitucionais, as leis e os regulamentos, os decretos e resoluções administrativas, entre outras". (2012, p.16).
}

Na cidade juazeirense são inúmeros os programas de Prefeitura voltados para a melhoria da cidade e bem-estar do cidadão, dentre eles podemos citar dois grandes projetos que se destacaram no município entre os anos de 2009 a 2018, são os programas Prefeitura nas Comunidades e Prefeitura Cidadã. Esses dois projetos de políticas públicas foram desenvolvidos em gestões diferentes, contudo a proposta desse artigo não é de fazer comparação entre as gestões e sim de discutir os desafios e contribuições que estes programas trouxeram e 
continuam trazendo para Juazeiro/BA.

Elaborado durante o Governo do prefeito Isaac Carvalho (2009-2016), "Prefeitura nas Comunidades", que já vinha sendo desenvolvido em outros municípios, é um programa de planejamento participativo o qual dividiu o município em 18 regiões administrativas entre área urbana e rural. O projeto foi executado através de plenárias nas regiões administrativas da sede e interior do município. Tendo como finalidade a descentralização das ações das secretarias e órgãos da administração pública, procurando envolver a população nas atividades desenvolvidas pela gestão municipal. O Programa Prefeitura Cidadã que iniciou-se em 2017, sob a gestão do Prefeito Paulo Bonfim e ainda em curso, vem se destacando também como um dos grandes programas de governo trazendo melhoria em vários setores do município e contando também com a participação ativa da população. O Programa dividiu o município em três regiões, onde a Região I e II refere-se aos bairros da zona urbana e a Região III os Distritos na zona rural. A proposta do programa é a democratização da gestão municipal de Juazeiro, garantindo a participação dos cidadãos por meios dos Conselhos Comunitários na aplicação e definição das prioridades das obras e dos serviços que são responsabilidades da prefeitura (JUAZEIRO/BA, 2018).

Embora implantados em gestões diferente "Prefeitura nas Comunidades" (2009-2016) e "Prefeitura Cidadã" (2017-) fundamentam-se em torno da participação do cidadão nas atividades desenvolvidas pela Prefeitura de Juazeiro. Os programas trouxeram várias ações e benefícios para os moradores juazeirenses e serviram como base para elaboração de outros projetos e programas que vem contribuindo com o desenvolvimento social, econômico e político de Juazeiro. Os programas da Prefeitura, como já foi analisado acima, são fundamentais para o planejamento, desenvolvimento e execução de ações inovadoras, eficiente e eficaz das políticas públicas empregadas em um município. Para isso é necessário incentivar a participação da população juazeirense no planejamento e definições das prioridades nas diversas áreas tais como educação, saúde, assistência social, habitação, trabalho, segurança, orçamento público, meio ambiente, transporte, cultura e esporte entre outros.

É importante destacar que são inúmeros os desafios e dificuldades que o poder Executivo enfrenta na efetivação desses programas de governos municipais. Falta de verba pública, a descrença populacional em seus representantes públicos, o descaso público, corrupção, troca de gestores, a oposição entre partidos são alguns dos numerosos impasses que 
devem ser avaliados e driblados.

Teixeira destaca,

\begin{abstract}
"Na sociedade civil também há uma diversidade de interesses e de visões que precisa ser debatida, confrontada, negociada, buscando-se um consenso mínimo. essa formulação hoje se torna complexa devido à fragmentação das organizações, apesar de algumas iniciativas de articulação em alguns setores. alguns elementos de conteúdo e de processo na estruturação das políticas públicas já estão claros, tais como: sustentabilidade, democratização, eficácia, transparência, participação, qualidade de vida. esses elementos precisam ser traduzidos contudo em parâmetros objetivos, para que possam nortear a elaboração, implementação e avaliação das políticas propostas". (2002, p.5).
\end{abstract}

Para que um programa obtenha sucesso e traga resultados, é de suma importância o envolvimento e comprometimento de todos os autores que compõem a esfera pública, principalmente a sociedade civil. Partindo do pensamento que ninguém constrói nada sozinho, é necessário que essa construção democrática rumo ao crescimento seja realizada coletivamente. Nesse sentido, Brant Carvalho (2012, p.49) enfatiza que "as políticas públicas dependem hoje de soluções que são democraticamente partilhadas entre Estado e sociedade". Para tal, é interessante que existam representantes políticos capazes de diagnosticar e analisar a realidade social, econômica e política da sociedade civil, negociando democraticamente com os diferentes autores envolvidos no processo, estabelecendo uma conexão entre as instituições políticas e as demandas coletivas. Andrade e Monteiro (2017, p.2) também afirmam, para que a democracia participativa deixe apenas de ser um direito abstrato, "é necessária uma sociedade civil atuante junto aos Conselhos Municipais, que conheça e cumpra seus deveres, assim como saiba exigir seus direitos, uma sociedade civil interessada e empenhada na invenção de uma nova sociedade".

Outro fator importante que devemos destacar é que nem sempre na implantação de uma política pública podem ser garantidos os resultados esperados e no prazo estimado. Como já mencionado acima. São inúmeras as dificuldades que podem surgir durante todo o processo, é por isso que um modelo de políticas públicas aplicados em um município deve ser aberto e flexível para se adaptar em todos os seus momentos de desenvolvimento conforme a realidade que ele vai enfrentando ao longo do processo. Como argumenta Dias e Matos (2012, p.15) "não existe um modelo de política publica "ideal” ou "correta", pois elas são respostas contingentes á situação de uma cidade, região ou um país". Cada município tem suas particularidades e 
experiências, o que funciona em um município pode não funcionar em outro. Sob essa perspectiva, é importante que os programas de políticas públicas estejam constantemente sendo avaliados quanto ao seu desempenho e resultados.

Uma das experiências mais debatidas na sociedade contemporânea dentro das políticas públicas é o Orçamento Participativo, que teve início em Porto Alegre/RS no ano de 1989, atualmente implantado em diversos municípios dos Estados brasileiros. Esse mecanismo governamental de participação do cidadão nas decisões sobre a aplicabilidade racional do orçamento público municipal vem se destacando cada vez mais na literatura, conferências e audiências públicas. O Orçamento Participativo é definido basicamente como um processo democrático participativo em que qualquer cidadão pode sugerir e decidir como será planejado o orçamento do seu município, quais áreas serão beneficiadas, além do retorno do Estado através da prestação de contas aos cidadãos, cooperando dessa forma, para a modernização da administração pública.

O Orçamento Participativo é um mecanismo democrático de políticas públicas orçamentárias no qual os cidadãos e a administração pública discutem em conjunto como e onde serão investidos os recursos orçamentários municipais. Nessa perspectiva, foi abolida a ideia de que o cidadão encerra sua participação política no ato de votar, e os governantes eleitos tem total liberdade para procederem como bem entenderem, o cidadão deixa agora de ser um simples coadjuvante para se tornar protagonista ativo da gestão pública. Os processos orçamentários participativos são executados geralmente por meio de reuniões abertas com etapas de negociação em que o governo considera as demandas prioritárias da população e o que deve ser incluído na Lei Orçamentária Anual do município. Nesse ponto tem-se uma visão clara de quanto o município tem no orçamento público e quanto dessa verba será destinado para cada demanda municipal, seja ela na área da educação, saúde, segurança, infraestrutura entre outras. "Trata-se de um processo de inclusão, que amplia as formas de participação política em vários sentidos" (VITALE, 2004, p.247). É importante que haja uma um bom planejamento do orçamento municipal, para que seja garantido a qualidade decisória nos investimentos municipais.

Para tal, foi criado o Ciclo do Orçamento Participativo, conhecido também como Ciclo Anual que estabelece os estágios para colocar em prática o Orçamento Participativo em um determinado município. A princípio o município é dividido em regiões menores para uma 
atuação mais eficaz na coleta e seleção de demandas de prioridades locais, com isso, as plenárias populares são baseadas na divisão regional de cada município. O Ciclo do Orçamento Participativo ocorre normalmente em duas rodadas. A primeira rodada referente às reuniões preparatórias que acontecem entre os meses de março e junho, compreendem a discussão principalmente da prestação de contas do ano anterior e a apresentação das regras do processo para o ano em curso. A segunda rodada do Ciclo de Orçamento Participativo é composta de Assembleias, compreendendo a deliberação das prioridades temáticas discutidas nas plenárias regionais e eleição dos conselheiros, geralmente composto por dois moradores de cada região, estes devem fiscalizar a elaboração das propostas orçamentárias, controlar a distribuição e votar alterações no procedimento; ocorrem também nessa segunda rodada a definição do número de delegados, execução, avaliação e prestação de conta pelo Poder Executivo. Existe ainda um Segundo Ciclo chamado Implementação do Ciclo de Supervisão, que começa no ano seguinte, voltado para aspectos administrativos, legais e técnicos, em que será elaborado o projeto de lei orçamentária anual (VITALE, 2004; MARQUETTI, 2007).

Conforme Bremaeker e Gonçalves,

\begin{abstract}
"A facilidade de adaptar o Orçamento Participativo a realidade dos municípios brasileiros é que torna possível que ele possa ser adotado em qualquer região do país, sendo o seu sucesso resultante do empenho dos gestores que a ele recorrem e não dependente de fatores sociais e econômicos. $\mathrm{O}$ fato das experiências vitoriosas com o OP acontecerem em municípios de regiões distintas do Brasil comprova pragmaticamente a flexibilidade do OP, que é planejado, formatado em conformidade com as características e as condições econômicas, sociais, políticas e até geográficas de cada município." (2015, p.8).
\end{abstract}

Contudo, existe discussão em torno da definição do modelo orçamentário participativo, resultante da propagação das experiências vivenciadas em Porto Alegre em diferentes contextos sociais e políticos, ou seja, podem existir variações do Ciclo de Orçamento Participativo de um município para o outro. Cada município tem suas particularidades e limites e o sucesso desse modelo democrático vai depender principalmente do interesse político e social, dos limites orçamentários do município, do modelo estrutural adotado e da capacidade deliberativa e cooperativa da sociedade civil. Para que se tenham resultados positivos no modelo de orçamento participativo adotado por um município, seu funcionamento exige a reciprocidade entre a esfera política e a sociedade civil (MARQUETTI, 2007; BODART, 2010).

No estado da Bahia uma das experiências participativas mais conhecidas é a do 
Orçamento Participativo que iniciou-se primeiramente na cidade de Vitória da Conquista no ano de 1997. Frente a uma série de dificuldades financeiras e administrativas e embates entre os partidos da oposição, a Prefeitura de Vitória da Conquista convocou os Conquistense para discutir e solucionar os problemas financeiro e administrativos no município. Instaurou-se desse modo, a participação democrática entre a prefeitura de Vitória de Conquista e seus cidadãos que juntos buscaram soluções para os problemas do município (NOVAES; SANTOS, 2014).

No município de Juazeiro/BA o Orçamento Participativo ainda é uma ideia vaga, visto que o programa não foi institucionalizado. O que se tem é um modelo que se assemelha ao do Orçamento Participativo, baseado nos programas da Prefeitura abordados acima. A participação popular juazeirense é observada principalmente nas plenárias e reuniões dos conselhos comunitários realizadas pelos programas da Prefeitura na Comunidade e Prefeitura Cidadã nas regiões administrativas e nas audiências públicas realizadas pela Prefeitura, onde são estabelecidas as demandas definidas pelos programas para elaboração na Lei de Diretrizes Orçamentárias do Município (LDO). Os moradores de cada região administrativa são convidados a participar das plenárias e reuniões comunitárias previamente agendadas, onde juntos com a prefeitura são apontadas as demandas e, à partir desse ponto feito um planejamento estratégico para as ações de governo.

De fato, a população juazeirense tem participado do planejamento do município, conforme as notícias divulgadas no site da prefeitura de Juazeiro que atestam a participação da população nas plenárias realizadas pelo programa Prefeituras nas Comunidades: "Prefeito, secretários municipais, equipe técnica de governo, vereadores, lideranças dos bairros e comunidade em geral participaram das atividades"; "agricultores, produtores rurais, donas de casa e estudantes lotaram a sessão da plenária participando ativamente do programa", "a associação esta fazendo uma mobilização de porta em porta no bairro para que ninguém deixe de participa”. Da mesma forma vem acontecendo no programa Prefeitura Cidadã a participação dos cidadãos nas reuniões dos conselhos comunitários: "Nestes encontros, permanentes, os moradores terão a oportunidade de dialogar com o poder público municipal, apresentando as demandas de cada comunidade, opinando, sugerindo e apontando caminhos, de forma a ajudar a prefeitura na qualidade dos serviços prestados"; "O Programa Prefeitura Cidadã reuniu milhares de moradores e lideranças comunitárias em todos os bairros na zona urbana e nos 
Distritos de Juazeiro"; "Estamos muito felizes com a participação significativa da população, que só foi possível devido à mobilização dos presidentes das associações de moradores, das lideranças e dos Comitês Intersetoriais de cada comunidade". (JUAZEIRO/BA, 2018).

Embora havendo a participação da população no planejamento do município falta uma maior transparência da continuidade das informações quanto aos resultados das audiências e o retorno da comunidade referente aos programas de governo realizados no município. Não existem informações acessíveis de que a participação da população juazeirense tem gerado consequências significativas nas situações financeiras do município de Juazeiro ou do tempo de execução ou dos custos envolvidos para atender as demandas deliberadas nas reuniões e plenárias e do acompanhamento do planejamento e execução das ações municipais.

É fundamental que no município o Orçamento Participativo como mecanismo de inovação pública, seja institucionalizado e regulamentado, assim como a Lei Orçamentária Anual de Juazeiro, considerando que a continuidade de muitos programas da Prefeitura, ficam vulneráveis às mudanças de gestão. Para que a participação do cidadão no orçamento público seja permanente e contínua, é necessário que seja garantida a estabilidade do processo por longo prazo, transformado o Orçamento Participativo numa realidade institucional, constante e independente da administração municipal, já que no Art. 30 da Lei de Diretrizes Orçamentárias (LEI No 2.300 de 06 de junho 2012) estabelece,

\begin{abstract}
"O Poder Executivo adotará mecanismos para incentivar a participação popular, na indicação de prioridades e na elaboração da Lei Orçamentária para exercício de 2013, bem como no acompanhamento e execução dos projetos contemplados, conforme disposto no art.48 da Lei Complementar n. ${ }^{\circ} 101$ de 04 de maio de 2000. Parágrafo Único. Os mecanismos previstos no caput deste artigo serão operacionalizados: I mediante audiências públicas ou consultas públicas, realizadas na Sede e nos Distritos, com a participação da população em geral, de entidades de classes, setores organizados da sociedade civil e organizações não governamentais; II - pela seleção conjunta através do disposto no inciso anterior, dos projetos prioritários, por cada área considerada, a serem incorporados na proposta orçamentária do exercício. III - nas audiências públicas ou consultas públicas serão adotadas formas de comunicação, acessíveis à comunidade, como meio de garantir a participação social democraticamente". (JUAZEIRO, 2012, p.12).
\end{abstract}

Frente aos avanços na democracia brasileira nas últimas décadas ainda existem muitos cidadãos brasileiros que por falta de informação desconhecem seus direitos e deveres, achando que sua participação se encerra nas urnas no dia das eleições, deixando os governantes decidirem por si só o futuro da sua cidade ou país. Thomas (2008) em seu trabalho intitulado 
"Os Caminhos da Cidadania" traz uma reflexão sobre a importância do cidadão em conhecer seus direitos. Ela diz que existe uma demagogia no que concerne às leis de proteção e respeito aos princípios e direitos de igualdade da população. As inúmeras promessas de melhoria no periodo eleitoral, acabam sendo esquecidas na maioria das vez, concluindo que existe o conhecimento da situação real da população, porém a falta de comprometimento impede que projetos ousados saiam do papel. Nesse sentido, é importante uma gestão política com maior transparência em que qualquer cidadão independente do nível social, educacional e econômico tenha conhecimento e acesso sobre os seus deveres e direitos junto às autoridades de seu município.

O cidadão de Juazeiro conta com o Portal da Transparência da Prefeitura de Juazeiro e o Portal de Transparência da Câmara dos Vereadores. Através desses veículos eletrônicos a população pode acompanhar o planejamento e a execução orçamentária municipal, conhecendo como o governo municipal aplica o dinheiro público. O Portal de transparência foi criado para que a população tenha acesso às informações sobre a aplicação dos recursos públicos garantindo uma maior transparência da gestão pública. Esses canais de comunicação permitem o cidadão acompanhar a execução orçamentária e financeira dos programas municipais, além de informações normativas e administrativas.

Conforme o Art. 48 da Lei Complementar n 101 de 04 de Maio de 2000, a transparência será assegurada mediante os

\begin{abstract}
“instrumentos de transparência da gestão fiscal, aos quais será dada ampla divulgação, inclusive em meios eletrônicos de acesso público: os planos, orçamentos e leis de diretrizes orçamentárias; as prestações de contas e o respectivo parecer prévio; o Relatório Resumido da Execução Orçamentária e o Relatório de Gestão Fiscal; e as versões simplificadas desses documentos.§ $1^{\circ} \mathrm{A}$ transparência será assegurada também mediante: I - incentivo à participação popular e realização de audiências públicas, durante os processos de elaboração e discussão dos planos, lei de diretrizes orçamentárias e orçamentos; II - liberação ao pleno conhecimento e acompanhamento da sociedade, em tempo real, de informações pormenorizadas sobre a execução orçamentária e financeira, em meios eletrônicos de acesso público; III - adoção de sistema integrado de administração financeira e controle, que atenda a padrão mínimo de qualidade estabelecido pelo Poder Executivo da União e ao disposto no art. 48A.” (BRASIL, 2000).
\end{abstract}

Em concordância com o Art. $2^{\circ}$ do Decreto n ${ }^{\circ} 7.18527$ de maio de 2010,

"O sistema integrado de administração financeira e controle utilizado no âmbito de cada ente da Federação, doravante denominado SISTEMA, deverá permitir a liberação em tempo real das informações pormenorizadas sobre a execução orçamentária e financeira das unidades gestoras, referentes à receita e à despesa, com 
a abertura mínima estabelecida neste Decreto, bem como o registro contábil tempestivo dos atos e fatos que afetam ou possam afetar o patrimônio da entidade". (BRASIL, 2010).

A Lei Complementar $n^{\circ} 101$ de 04 de maio de 200, no parágrafo $2^{\circ}$ da Transparência da Gestão Fiscal também dispõe,

“A União, os Estados, o Distrito Federal e os Municípios disponibilizarão suas informações e dados contábeis, orçamentários e fiscais conforme periodicidade, formato e sistema estabelecidos pelo órgão central de contabilidade da União, os quais deverão ser divulgados em meio eletrônico de amplo acesso público" (BRASIL, 2016).

O acesso a informações com transparência também é assegura pelo DECRETO Nº 565 de 20 de outubro de2016,

\begin{abstract}
“Art. $2^{\circ}$ Os órgãos e as entidades do Poder Executivo Municipal assegurarão às pessoas físicas e jurídicas o direito de acesso à informação, proporcionada mediante procedimentos objetivos e ágeis, de forma transparente, clara e em linguagem de fácil compreensão". Art. $7^{\circ}$ É dever dos órgãos e entidades promoverem, sempre que possível e independente de requerimento, à divulgação em seus sítios eletrônicos de informações de interesse coletivo ou geral por eles produzidas ou custodiadas" (JUAZEIRO/BA, 2016).
\end{abstract}

Diante de inúmeras leis que garantem a transparência das informações das ações orçamentárias, é responsabilidade do cidadão também o interesse pela procura dessas informações. Não basta responsabilizar somente os governantes, quando nem mesmo o próprio cidadão procura conhecer quais são os seus direitos e deveres. Exigir seus direitos é parte da cidadania, mas muitas vezes nos esquecemos de que quando negligenciamos o nosso papel dentro da sociedade ignoramos que as nossas atitudes e ações individuais se refletem num coletivo e acabamos prejudicando a todos, impedindo que seja construída uma cidadania como a qual sonhamos. Os portais da transparência, as informações de contato, a ouvidoria, Serviço de Informações ao Cidadão - SIC, foram criados e estão a disposição para atender e orientar o público quanto ao acesso à informação, o que falta é o cidadão querer fazer valer seus direitos ao acesso as informações da sua cidade.

Thomas diz,

"Ninguém é cidadão na individualidade, enquanto seres humanos, o homem se realiza no coletivo, na socialização, sendo, portanto, construtor da sua história e da história da sua comunidade, do seu país. E para isso, o indivíduo precisa conhecer os seus direitos, deveres e responsabilidades". (2008, p.94). 
Como observado anteriormente, existem Leis e Decretos que assegurem a participação do cidadão juazeirense no planejamento do orçamento municipal e ao acesso dos resultados desse planejamento. Entretanto, vale ressaltar que não bastam as inúmeras leis e decretos assegurando que todos têm direito a participação e acesso de informações, é fundamental que sejam garantidos através do exercício desses direitos previstos e regulamentados.

Como afirma Gadotti,

"É fundamental que sejam garantidos através do exercício desses direitos previstos e regulamentados. Mas não basta criar mecanismos de participação popular e de controle social das políticas públicas; é preciso atentar para a necessidade de criar, também, simultaneamente, as condições de participação. A participação popular não pode ser alguma coisa episódica, paralela, mas estrutural; ela deve constituir-se numa metodologia permanente da política, num modo de governar". (2014, p.12)

As políticas públicas estão por todas as partes na nossa sociedade, no entanto para que haja avanço e sucesso na sua formulação e implantação, cabe a cada cidadão o interesse de querer se libertar de um governo de supremacia e de uma sociedade alienada e desinteressada, promovendo um país mais democrático e participativo, que faça valer os direitos constitucionais de seus cidadãos. Thomas (2008), afirma que além de outras tantas declarações, leis, decretos, portarias, que determinam os procedimentos, cuidados, direitos e deveres da população, cabe ao cidadão o dever de estar sempre atento e participando do que está acontecendo ao seu entorno.

\section{Conclusões}

As políticas públicas sem dúvida são um instrumento inovador de aproximação do cidadão com o poder público. É através delas que se constrói uma sociedade democrática, valendo-se dos deveres e direitos do Estado e da sociedade civil, visando o benefício da coletividade e formação da cidadania. Nesse ponto, a Gestão Social e o Orçamento Participativo no âmbito municipal, enquanto garantia de direitos, que se concretiza por meio de Políticas Públicas, são formas democráticas de envolvimento participativo da sociedade civil no que diz respeito principalmente à condução dos gastos e investimentos pelas autoridades políticas municipais. 
A participação democrática do cidadão, considerada um avanço na democracia brasileira, é de extrema importância na elaboração e implantação das políticas pública do município, visto que a participação da sociedade nas tomadas de decisões é indispensável para o controle da gestão pública. A sociedade passa a ter voz ativa nas decisões políticas e orçamentárias da sua cidade. Percebemos que população juazeirense sem dúvidas tem participado ativamente no planejamento orçamentário municipal. Segundo as informações divulgadas no site da prefeitura, os moradores onde já foram realizadas as plenárias e reuniões comunitárias, tem recebido de forma positiva a iniciativa da prefeitura, através dos programas "Prefeitura nas Comunidades" e "Prefeitura Cidadã".

Embora quando consideramos os ciclos das políticas públicas em Juazeiro, verificamos que faltam mais informações e transparência sobre os avanços e resultados e continuidade das plenárias e reuniões comunitárias, o que se tem de conhecimentos são as poucas notícias publicadas no site da Prefeitura e em blogs particulares. Não se tem informação em tempo real sobre o processo de monitoramento e controle das demandas e planejamentos orçamentário e sobre até que ponto as demandas da comunidade são atendidas e quais prioridades prevalecem nas audiências de planejamento orçamentário do município. Necessita-se de maior divulgação de informações, de forma mais detalhadas e, de documentos mais acessíveis que relatem todo o acompanhamento da execução dos programas, sobretudo do planejamento e dos resultados orçamentários do município.

A prefeitura de Juazeiro vem caminhando na direção certa nos últimos anos, incentivando a participação do cidadão no planejamento de melhorias para o município. Verificou-se efeitos relavantes dessa participação na descentralização da gestão municipal, quando a prefeitura criou programas que permitiram à população, maior envolvimento no planejamento orçamentário do município, construindo-se assim, uma gestão mais justa e igualitária.

Contudo, muitos são grandes os desafios e dificuldades, que giram em torno da ideia de Políticas Públicas, sobretudo de Orçamento Participativo em Juazeiro. Acredita-se que, com o cumprimento das responsabilidades da gestão municipal e, com um maior envolvimento e interesse dos cidadãos juazeirenses, esses desafios e dificuldades podem ser driblados, garantindo-se dessa forma, o fortalecimento e o desenvolvimento econômico e social da cidade, na construção de uma nova gestão. 


\section{Referências}

ANDRADE, P.B.L.; MONTEIRO, E.R. A participação social nos Conselhos Gestores do Município de Sumidouro/RJ. UFF. 2017.

BARBOSA, J.L. Política pública, gestão municipal e participação social na construção de uma agenda de direitos à cidade. Scripta Nova, v. 14, n.331, p. 1-7, 2010.

BORDAT, C. N.Capital social e orçamento participativo: uma revisão crítica de alguns autores. Revista Mediações, v. 15, n.2, p. 304-323, 2010.

BRANT CARVALHO, M. C. Gestão social e políticas públicas: uma questão ainda em debate no século XXI. Inl: JUNQUEIRA, L. A. P.; DIAS, S. L. F. G, WANDERLEY, M. B., MENDONÇA, P.Gestão social: mobilizações e conexões. São Paulo: LCTE, 2012. p. 42-56.

BRASIL. Lei Complementar $n^{o}$ 101, de 4 de maio de 2000. Estabelece normas de finanças públicas voltadas para a responsabilidade na gestão fiscal e dá outras providências. Brasília: Diário Oficial da União de 05/05/2000.

BRASIL. Lei $n^{o}$. 10.257, de 10 de julho de 2001. Estabelece diretrizes gerais da política urbana. Estatuto da Cidade: guia para implementação pelos municípios e cidadãos. Brasília: Câmara dos Deputados, Brasília, 2001.

BRASIL. Decreto $n^{\circ} 7.185$, de 27 de maio de 2010.Dispõe sobre o padrão mínimo de qualidade do sistema integrado de administração financeira e controle, no âmbito de cada ente da Federação, nos termos do art. 48, parágrafo único, inciso III, da Lei Complementar no ${ }^{\circ}$ 101, de 4 de maio de 2000, e dá outras providências, Brasília, 2010.

BREMAEKER, F.E.J.; GONÇALVES, L.E. A prática do orçamento participativo. Observatório de Informações Municipais. 2015.

DIAS, R.; MATOS, F. Políticas Públicas - Princípios, Propósitos e Processos. São Paulo: Atlas, 2012, 264p.

GODATTI, M. Uma tecnologia social genuinamente brasileira e um direito humano fundamental. Inl:Orçamento participativo: múltiplos olhares. LIMA, K.C.P.; OLIVEIRA PINI, F.R. São Paulo: Instituto PauloFreire, 2014. 207p.

INSTITUTO BRASILEIRO DE GEOGRAFIA E ESTATÍSTICA-IBGE. Cidades@:Juazeiro.

Disponível em:.https://cidades.ibge.gov.br/brasil/ba/juazeiro/panorama. Acesso em: 01 de out. de 2018.

JUAZEIRO (BA). Lei Municipal $N^{o}$. 1.767, 22 de dezembro de 2003. Institui o Plano Diretor de Desenvolvimento Urbano de Juazeiro e das providências. Juazeiro, 2003.

JUAZEIRO (BA). Lei $N^{o} 2.300$ de 06 de junho de 2012.Dispõe sobre as diretrizes orçamentárias para o exercíciode 2013 e dá outras providências. Juazeiro, 2012. 
JUAZEIRO (BA).Decreto $N^{o} 565,20$ de outubro de 2016. Regulamenta o acesso à informação pública pelo cidadão nos termos da Lei Federal n ${ }^{\circ}$ 12.527, de 18 de novembro de 2011, no âmbito do Município de Juazeiro/BA e dá outras providências. Juazeiro, 2016.

JUAZEIRO/BA. Prefeitura Municipal de Juazeiro. Portal da Transparência. Disponível em: <https://www6.juazeiro.ba.gov.br/>. Acesso em: 29 de Set. de 2018.

MARQUETTI, A. Experiências de orçamento participativo no Brasil: uma proposta de classificação. Inl: DAGNINO, Evelina; TATAGIBA, Luciana. Democracia, sociedade civil e participação. Chapecó: Argos, 2007. p.77

NOVAES, F.S.; SANTOS, M. E. P.; O Orçamento Participativo e a democratização da gestão pública municipal - a experiência de Vitória da Conquista (BA). Revista de Administração Pública, v. 48, n. 4, p 797-820, 2014.

OLIVEIRA, V.A.R.; CAÇANDO, A.C.; PEREIRA, J.R. Gestão social e esfera pública: aproximações teórico-conceituais. Cadernos EBAPE, v. 8, nº 4, p.613-626, 2010.

ROCHA, R. A gestão descentralizada e participativa das políticas públicas no Brasil. Revista Pós Ciências Sociais, v. 1, n. 11, p. 3-30, 2009.

SILVA, A.C.S.; RODRIGUES, D.R.N.; TIBALDI, S.D. Nudges e políticas públicas: um mecanismo de combate ao trabalho em condição análoga à de escravo. Revista Brasileira de Políticas Públicas, v.8, n.2, p. 267-286, 2018.

SANTOS, S. T. G.; PINHEIRO, C. E. F. Gestão social: considerações da importância em conselhos de políticas pública. Revista Serviço Social em Perspectiva, v.1, n. 1, p. 201-216, 2017.

TEIXEIRA, E. C. OPapel das Políticas Públicas no Desenvolvimento Local e na Transformação da Realidade. Associação de Advogados de Trabalhadores Rurais da Bahia 2002.

THOMAS, L. Caminhos da Cidadania. Secretaria de Estado da Educação -Parana, 2008, p.95.

VITALE, D. Democracia direta e poder local: a experiência brasileira do Orçamento Participativo. Inl: COELHO, V.S.P.; NOBRE, M. Participação e Deliberação: Teoria democrática e experiências institucionais no Brasil contemporâneo. São Paulo: Editora 34, 2004,p.255-269.

\section{Como citar este artigo (Formato ABNT):}

MOTA, Alexsandro de Jesus; SANTOS, Marcelo Henrique Pereira dos. Orçamento Participativo e Gestão Social: O Município de Juazeiro/BA e suas experiências participativas. Id on Line Rev.Mult. Psic., 2018, vol.12, n.42, Supl. 1, p. 180-197. ISSN: 1981-1179.

Recebido: 02/11/2018;

Aceito: 05/11/2018 